\title{
Plantas medicinais no tratamento do câncer: uma breve revisão de literatura
}

\author{
Lorena Gomes de Moraes ${ }^{1}$ \\ Araci Molnar Alonso ${ }^{2}$ \\ Eduardo Cyrino Oliveira-Filho ${ }^{3}$
}

\section{Resumo}

O câncer, nas suas diversas formas, é uma doença que atinge o mundo todo e, no Brasil, é a segunda maior causa de mortes em adultos. O seu aparecimento e desenvolvimento estão ligados ao estilo de vida das pessoas e aos fatores ambientais a que elas se expõem. Dentre os diversos usos terapêuticos atribuídos às plantas medicinais, a fitoterapia é o tratamento das doenças pelo uso de plantas frescas ou dessecadas e pelos seus extratos naturais. Nos últimos anos, ela vem sendo retomada pela medicina convencional como uma forma mais acessível e alternativa de tratamento, e sua importância vem crescendo consideravelmente, inclusive no combate ao câncer. Porém é grande a preocupação quanto ao uso caseiro das plantas medicinais, pois sua utilização inadequada e sem critério pode trazer graves consequências. Por esse fato, pesquisas nessa área e formas de controle e orientação à população em geral devem ser desenvolvidas. Assim, o objetivo deste trabalho é realizar uma breve revisão quanto à utilização de plantas medicinais no tratamento do câncer.

Palavras-chave: Câncer. Plantas medicinais. Medicina não convencional. Fitoterapia. Anticancerígeno.

\section{Introdução}

A cada ano são diagnosticados cerca de 1,2 milhões de novos casos de câncer invasivo nos Estados Unidos, sendo que por volta de 500.000 pessoas morrem

1 Graduada em Biomedicina, pelo Centro Universitário de Brasília - UniCEUB. Email: logmoraes@hotmail.com

2 Pesquisadora da Embrapa Cerrados. Email: araci.alonso@cpac.embrapa.br

3 Professor do Centro Universitário de Brasília - UniCEUB e pesquisador da Embrapa Cerrados. Email: eduardo.cyrino@uniceub.br 
anualmente (SIMONE, 2001). No Brasil, a doença representa a segunda causa de morte em adultos (CÂNCER..., 2004). Uma das áreas médicas que mais evolui e mobiliza a sociedade é a oncologia. Com o controle das doenças agudas, o desafio está sendo controlar as crônico-degenerativas, nas quais predominam os cânceres e as doenças cardíacas (KLIGERMAN, 1999).

\subsection{Aspectos gerais sobre o câncer}

O corpo humano possui um mecanismo preciso que controla o crescimento de diferentes órgãos, para que atinjam um tamanho específico. Na maior parte dos órgãos, podemos encontrar um mecanismo de reparo e suporte, cuja função é reparar e recuperar o tecido do órgão caso ele seja danificado em decorrência de alguma lesão. As células sobreviventes se proliferam, substituindo as lesadas, e o processo cessa assim que o dano é reparado. Esse mesmo mecanismo funciona também para a substituição constante das células que vão envelhecendo e morrendo naturalmente (FRANKS, 1990). Segundo Otto (2002), o câncer pode ser definido como um processo lógico em que células normais, por sofrerem modificações, passam a ter capacidades especiais. Essas células modificadas são conhecidas como cancerígenas e se dividem de maneira sucessiva formando assim um agrupamento de células malignas que são idênticas, causando mutações que vão determinar um novo comportamento delas, como um crescimento mais acelerado (ABCÂNCER, 2008). Essas células têm a capacidade de criar novos vasos sanguíneos, que vão nutri-las, mantendo a sua atividade de crescimento. Podem também se disseminar através de vasos sanguíneos ou linfáticos, atingindo órgãos distantes do local de sua origem, fenômeno conhecido como metástase. Assim, conforme os tecidos vão sendo invadidos, eles vão perdendo as suas funções, e por isso, uma pessoa que desenvolve um câncer tem fortes sintomas que são característicos de acordo com o local atingido (INSTITUTO NACIONAL DO CÂNCER, 2008a).

O resultado desse acúmulo de células é a formação de tumores, que podem ser benignos ou malignos. Um tumor benigno é aquele cujas células são semelhantes ao seu tecido de origem e apresentam um crescimento lento. Esse tipo de tumor raramente representa um risco de morte para o indivíduo, podendo, quase sempre, 
ser completamente removido por cirurgia. Já um tumor maligno tende a ser mais agressivo e apresentar características particulares, como a anormalidade celular e a metástase, o que torna o seu diagnóstico mais fácil. Mudanças como variação no tamanho e na forma da célula, aumento do tamanho nuclear e densidade da coloração, e perda da distribuição regular das células são indicativos desse tipo de tumor (FRANKS, 1990).

Segundo Brown e colaboradores (1994), o começo de um câncer pode ser causado por uma alteração irreversível do DNA, material que está presente em todas as células do nosso corpo e que controla as suas atividades normais, e ainda por uma replicação e proliferação celular, fixando-se a mutação inicial. Para se ter uma proteção contra essa modificação, é necessária a existência de mecanismos de detoxificação de carcinógenos, de eliminação das células afetadas e de reparos desse DNA, que impeçam a formação de células cancerígenas. Todavia, nem sempre o nosso corpo tem a capacidade de ativar tais mecanismos, o que permite que as células comecem a se proliferar. Os carcinógenos são elementos nocivos que podem levar a uma maior probabilidade de lesões no DNA, aumentando as chances de uma neoplasia (SASSE, 2004). Como exemplos desses carcinógenos, podem ser citados os agentes que estão ligados às profissões e ao ambiente, como a fuligem a que estão expostas as pessoas que trabalham na limpeza de chaminés; os vírus, que podem causar câncer em mamíferos; os medicamentos e agentes de irradiação e os fatores genéticos e imunológicos (BERTINO, 1980). Estudos epidemiológicos indicam que de todos os casos de câncer, aproximadamente $80 \%$ estão associados a fatores ambientais (BODMER, 1990). O câncer também pode estar associado à idade, sexo e histórico familiar, tornando-o difícil de ser controlado. Quando se fala em fatores ambientais e estilo de vida, eles se referem aos fatos que podem ser mudados, como, por exemplo, uma pessoa que fuma e por isso tem mais chances de desenvolver um câncer de pulmão do que uma pessoa que nunca fumou (AMERICAN CANCER SOCIETY, 2008).

As áreas do corpo humano que podem ser afetadas por um câncer são: cabeça e pescoço, pulmão e pleura, pele, mama, sistema digestório, ginecológico e urológico, ossos, partes moles, sangue (leucemia), muito comum em crianças, e outras (INSTITUTO NACIONAL DO CÂNCER, 2008c). A tabela 1 mostra a es- 
timativa de novos casos de câncer, no ano de 2008, em regiões do Brasil. Pode-se observar que a Região Sudeste é a que apresenta a maior quantidade de casos em todas as localizações primárias, provavelmente por concentrar a maior parte da população do país. Em todas as regiões, o câncer de pele não melanoma se apresenta mais frequentemente. No Sul, os cânceres de mama e de próstata estão em segundo lugar; no Norte, Nordeste e Centro-Oeste, o câncer de próstata é o que ocupa essa posição e, no Sudeste, observamos o câncer de mama.

\subsection{Aspectos gerais sobre o uso de plantas medicinais}

Quando se aborda o tema plantas medicinais, inicialmente é fundamental apresentar alguns conceitos importantes em fitoterapia como, plantas medicinais, princípio ativo, a própria fitoterapia e produto fitoterápico, termos obtidos em Oliveira e Akisue (1997), na literatura intitulada Fundamentos de Farmacobotânica, e apresentados abaixo.

Tabela 1 - Estimativa para o ano 2008 de casos novos de câncer, por região do Brasil, com números arredondados para 10 ou múltiplo de 10 .

\begin{tabular}{cccccc}
\hline Localização Primária & Norte & Nordeste & Centro-Oeste & Sul & Sudeste \\
\hline Mama Feminina & 1.210 & 7.630 & 2.630 & 9.500 & 28.430 \\
\hline $\begin{array}{c}\text { Traqueia, Brônquio e } \\
\text { Pulmão }\end{array}$ & 1.020 & 3.630 & 1.690 & 7.210 & 13.720 \\
\hline Estômago & 1.200 & 3.840 & 1.250 & 4.360 & 11.150 \\
\hline Próstata & 1.750 & 9.820 & 3.200 & 9.500 & 25.260 \\
\hline Colo do Útero & 1.700 & 4.720 & 1.350 & 3.470 & 7.440 \\
\hline Colón e Reto & 550 & 2.680 & 1.430 & 5.950 & 16.380 \\
\hline Esôfago & 230 & 1.360 & 560 & 3.110 & 5.290 \\
\hline Leucemias & 530 & 1.900 & 650 & 1.820 & 4.640 \\
\hline Cavidade Oral & 400 & 2.500 & 750 & 2.500 & 8.010 \\
\hline Pele Melanoma & 150 & 450 & 250 & 1.950 & 3.120 \\
\hline Outras Localizações & 4.550 & 14.190 & 7.260 & 27.270 & 64.610 \\
\hline Subtotal & 13.290 & 52.720 & 21.020 & 76.640 & 188.050 \\
\hline Pele Não Melanoma & 4.330 & 26.240 & 7.490 & 22.940 & 54.010 \\
\hline Total & 17.620 & 78.960 & 28.510 & 99.580 & 242.060 \\
\hline
\end{tabular}

Fonte: Instituto Nacional do Câncer (2008b).

a) planta medicinal: é todo vegetal que contém em um ou em vários de seus órgãos substâncias que podem ser empregadas para fins terapêuticos ou precursores de substâncias utilizadas para tais fins; 
b) princípios ativos: são substâncias quimicamente definidas, presentes nas matérias-primas e nos fitoterápicos responsáveis pela atividade farmacodinâmica, ou seja, pelos efeitos terapêuticos desses materiais;

c) fitoterapia: é o método de tratamento de enfermidades que emprega vegetais frescos, drogas vegetais ou, ainda, extratos vegetais preparados com esses dois tipos de matérias primas. A droga vegetal é a planta ou suas partes que, após coleta, preparo e conservação (secagem, estabilização) justifique seu emprego na preparação de medicamentos, dos quais uma das características é a presença de princípios ativos;

d) produto fitoterápico: é todo medicamento obtido e elaborado empregando-se exclusivamente matérias-primas vegetais ativas com finalidade curativa ou profilática com benefício para o usuário.

Segundo Mota et al. (2004), a primeira forma de uso de medicamentos de que se tem conhecimento, seria o uso de plantas medicinais. Existem registros que relatam a utilização de plantas pelo homem desde a Antiguidade. Acredita-se também que elas eram usadas para a cura de doenças, então consideradas como castigos ou fúria dos deuses (NEVES, 2007).

Aos poucos, remotas civilizações primitivas foram percebendo que, dentre as plantas comestíveis, existiam aquelas com maior ou menor toxicidade, e que muitas demonstravam certo poder curativo no combate às doenças. Assim, tudo o que era descoberto ia sendo passado, oralmente, de geração em geração, até o aparecimento da escrita. Essas informações eram guardadas como um tesouro precioso (SOARES et al., 1998).

A Organização Mundial de Saúde (OMS) estima que o uso de algum tipo de medicina tradicional, popular, para cuidados básicos da saúde, seja realizado em aproximadamente $80 \%$ da população mundial, sendo que $85 \%$ dos tratamentos envolvem plantas medicinais (NEVES, 2007). Segundo Yunes, Pedrosa e Filho (2001), a fitoterapia vem crescendo de forma notável nos últimos anos, alcançando no mercado mundial de fitoterápicos um valor em torno de 22 bilhões de dólares. 
Apesar de possuir um grande número de grupos de pesquisas e a maior reserva de biodiversidade do mundo, o Brasil não tem uma forte atuação no mercado mundial de fitoterápicos, perdendo até para países tecnologicamente menos desenvolvidos.

De acordo com a Resolução da Diretoria Colegiada, (RDC) n 48/2004, da Agência Nacional de Vigilância Sanitária (ANVISA), os fitoterápicos são medicamentos obtidos de matérias-primas ativas vegetais retiradas de partes específicas das plantas medicinais (folha, raiz, casca, flores, frutos ou sementes), e são conhecidos pela eficácia e pelos riscos que podem apresentar, sendo a segurança de seu uso estabelecida por meio de levantamentos etnofarmacológicos de utilização, e documentações técnico-científicas contidas em publicações. As características terapêuticas de plantas são descritas com frequência em diversos estudos, e isso se dá pelo fato de existirem usuários de fitoterápicos no mundo inteiro. Além disso, as observações populares sobre o uso e a eficácia das plantas contribuem para esse tipo de pesquisa, onde diversas áreas multidisciplinares podem ser envolvidas, como a botânica, a farmacologia e a fitoquímica (MACIEL et al., 2002).

É comum, em diversos países, o costume de se cultivar plantas nos quintais de casas, em hortas, jardins ou, até mesmo, em pequenos recipientes (LUZ, 2001), o que evidencia que o uso e o acesso a essas plantas permanecem na cultura desde tempos remotos até a atualidade.

Nesse contexto, o objetivo deste trabalho é apresentar uma breve revisão sobre a utilização de plantas medicinais para o tratamento do câncer.

\section{0 uso de plantas medicinais como método complementar}

Nos últimos 20 anos, o diagnóstico e o tratamento de vários tipos de câncer sofreram um grande avanço, mediante o uso de métodos de biologia molecular, análises bioquímicas e modernos métodos de imagens, que permitem um diagnóstico adequado do paciente, acompanhado de tratamentos que envolvem radioterapia, quimioterapia, cirurgia e transplante de medula óssea (CÂNCER..., 2004). 
Hoje em dia, um grande número de pessoas portadoras de câncer recorre a diversas possibilidades para tentar buscar a sua cura, considerando assim a possibilidade de uso da medicina não convencional. Apesar desse tipo de medicina apresentar um uso crescente a cada dia, o seu funcionamento não é conhecido adequadamente por grande parte das pessoas que a usam, principalmente por não receberem esclarecimentos sobre o assunto (ELIAS; ALVES; TUBINO, 2006).

O uso de métodos terapêuticos complementares ou alternativos preocupa os profissionais de saúde que trabalham com pacientes oncológicos, pois temem o risco de o doente abandonar a medicina tradicional e se tratar somente com a não convencional, podendo prejudicar o seu tratamento, principalmente na fase inicial (FLETCHER, 1992).

Nesse contexto, Araújo et al. (2007) realizaram uma pesquisa em hospitais da rede pública de saúde de João Pessoa, onde pacientes com câncer foram entrevistados por meio de questionários. Essa entrevista teve como objetivo avaliar o uso de plantas medicinais pelos doentes e verificar os seus conhecimentos. No total, 40 portadores de câncer foram entrevistados. Desses, 47,5\% afirmaram fazer o uso de alguma planta medicinal. Dentre os confirmados, 58\% relataram não usar a planta isoladamente, três revelaram utilizar a planta juntamente com a radioterapia, cinco utilizavam mais de uma planta por vez e três afirmaram fazer o uso associado com os remédios prescritos. A maioria dos pacientes revelou ter começado a usar as plantas por indicação de amigos ou familiares, 79\% não informavam aos médicos sobre o uso e todos disseram terem sentido uma melhora relativa nos sintomas. A relação das 13 plantas citadas pelos pacientes está apresentada na Tabela 2. Muitas delas foram utilizadas para diminuir os efeitos colaterais da quimioterapia ou para combater complicações da própria doença. 
Tabela 2 - Plantas medicinais relatadas por portadores de câncer entrevistados em hospitais da rede pública de saúde em João Pessoa (PB).

\begin{tabular}{|c|c|c|c|c|c|}
\hline $\begin{array}{l}\text { Nome popular e } \\
\text { científico } \\
\text { da planta medicinal }\end{array}$ & Indicação & $\begin{array}{l}\text { Parte } \\
\text { usada }\end{array}$ & $\begin{array}{l}\text { Forma de } \\
\text { uso }\end{array}$ & Preparação & $\begin{array}{l}\text { Local de } \\
\text { obtenção }\end{array}$ \\
\hline $\begin{array}{l}\text { Alho } \\
\text { (Allium sativum L.) }\end{array}$ & $\begin{array}{c}\text { Hipertensão, } \\
\text { colesterol alto } \\
\text { e câncer }\end{array}$ & Bulbo & $\begin{array}{l}\text { Misturado } \\
\text { c/ álcool; } \\
\text { ingerir o } \\
\text { bulbo }\end{array}$ & In natura & $\begin{array}{l}\text { Nas feiras e } \\
\text { nos super- } \\
\text { mercados }\end{array}$ \\
\hline $\begin{array}{l}\text { Aroeira } \\
\text { (Schinus terebinthifo- } \\
\text { lius Raddi) }\end{array}$ & $\begin{array}{l}\text { Inflamação e } \\
\text { câncer }\end{array}$ & Casca & $\begin{array}{l}\text { Banho de } \\
\text { assento }\end{array}$ & Decocto & Nas feiras \\
\hline $\begin{array}{l}\text { Babosa } \\
\text { (Aloe vera }(L) \text { Burm. } \\
\text { f.) }\end{array}$ & Câncer & $\begin{array}{l}\text { Toda a } \\
\text { planta }\end{array}$ & Garrafada & $\begin{array}{l}\text { Misturada c/ } \\
\text { cachaça }\end{array}$ & $\begin{array}{l}\text { Nas feiras e } \\
\text { na própria } \\
\text { residência }\end{array}$ \\
\hline $\begin{array}{l}\text { Babatenon } \\
\text { (Stryphnodendron } \\
\text { adstringens (Mart.) } \\
\text { Coville) }\end{array}$ & Ferimentos & Casca & Chá & Decocto & Nas feiras \\
\hline $\begin{array}{l}\text { Boldo } \\
\text { (Peumus boldus } \mathrm{Mol} \text { ) }\end{array}$ & $\begin{array}{l}\text { Digestão } \\
\text { difícil }\end{array}$ & - & Chá & Infuso & $\begin{array}{l}\text { Nas feiras e } \\
\text { nos super- } \\
\text { mercados }\end{array}$ \\
\hline $\begin{array}{l}\text { Camomila } \\
\text { (Matricaria chamo- } \\
\text { milla L.) }\end{array}$ & Nervosismo & Folha & Chá & Decocto & $\begin{array}{l}\text { Nas feiras e } \\
\text { nos super- } \\
\text { mercados }\end{array}$ \\
\hline $\begin{array}{l}\text { Capim-santo } \\
\text { (Cymbopogon citratus } \\
\text { DC. Stapf) }\end{array}$ & Calmante & Folha & Chá & Infuso & $\begin{array}{l}\text { Na própria } \\
\text { residência }\end{array}$ \\
\hline $\begin{array}{l}\text { Cajueiro roxo } \\
\text { (Anacardium occiden- } \\
\text { tale L.) }\end{array}$ & Inflamação & Casca & Chá & Decocto & Nas feiras \\
\hline $\begin{array}{l}\text { Erva-doce } \\
\text { (Pimpinella anisum } \\
\text { L.) }\end{array}$ & $\begin{array}{l}\text { Insônia, es- } \\
\text { timulante do } \\
\text { apetite e cóli- } \\
\text { cas infantis }\end{array}$ & Semente & $\begin{array}{l}\text { Chás; } \\
\text { temperos }\end{array}$ & Infuso & $\begin{array}{l}\text { Nos super- } \\
\text { mercados }\end{array}$ \\
\hline $\begin{array}{l}\text { Ginseng } \\
\text { (Panax ginseng C. A. } \\
\text { Meyer) }\end{array}$ & Estimulante & - & Cápsulas & Oral & Nas farmácias \\
\hline $\begin{array}{l}\text { Ipê-roxo ou pau } \\
\text { d'arco (Tabebuia } \\
\text { avellanedae Lor. ex. } \\
\text { Griseb) }\end{array}$ & $\begin{array}{l}\text { Inflamação e } \\
\text { câncer }\end{array}$ & Casca & $\begin{array}{l}\text { Ingestão c/ } \\
\text { água }\end{array}$ & Tintura & $\begin{array}{l}\text { Obtinham } \\
\text { pronto }\end{array}$ \\
\hline $\begin{array}{l}\text { Jatobá } \\
\text { (Hymenaea courbaril } \\
\text { L.) }\end{array}$ & Inflamação & Raspa & Chá & Decocto & $\begin{array}{l}\text { Com a vizi- } \\
\text { nhança }\end{array}$ \\
\hline $\begin{array}{l}\text { Romã } \\
\text { (Punica granatum L.) }\end{array}$ & Inflamação & $\begin{array}{l}\text { Casca do } \\
\text { fruto }\end{array}$ & Gargarejo & Decocto & Nas feiras \\
\hline
\end{tabular}

Fonte: (ARAÚJO et al., 2007). 
O alho (Allium sativum L.) está entre as primeiras especiarias cultivadas no mundo, sendo facilmente identificado pelo seu odor característico. O seu conhecimento na medicina popular se dá através de séculos, e é utilizado para tratamento de diversos problemas como gripe, queimaduras, feridas, dores de cabeça, doenças respiratórias, diabetes, desordens cardiovasculares e câncer (BLOCK et al., 1993). Muitos pesquisadores têm relatado provas farmacológicas, sustentando a sua utilização como um agente anticancerígeno. Uma série de compostos do enxofre, extraídos e identificados a partir do alho, tem demonstrado possuir essas propriedades. Por meio de muitos estudos, relatou-se que os mecanismos de supressão da iniciação e do desenvolvimento do câncer têm relação com esses componentes isolados, e que são realmente poderosos agentes antineoplásicos (THOMSON; ALI, 2003).

O alho também possui atividade antioxidante que, atualmente, vem sendo bastante estudada (BHUVANESWARI et al., 2004).

A aroeira (Schinus therenbithifolius Raddi) é uma árvore pequena, de ramos foliosos e possui frutos globulosos, avermelhados e pequenos. É indicada para combater febres, reumatismo e sífilis. Também é aconselhada em casos de atonia muscular, distensão de tendões, artrite, reumatismo, fraqueza dos órgãos digestivos e tumores linfáticos (BALBACH, 1995).

A babosa (Aloe vera (L) Burm. f.) é uma planta de folhas carnosas, que também pode ser encontrada nas partes secas da África e nas montanhas da África Tropical. O suco de suas folhas é emoliente e resolutivo, podendo ser usado em inflamações e queimaduras, e as folhas despidas são indicadas para contusões e dores reumáticas (BARRACA, 2008). Atualmente é utilizada na medicina moderna em muitos lugares do mundo, além de estar presente na indústria cosmética, farmacêutica e alimentar (VEGA et al., 2005).

O barbatimão (Stryphnodendron adstringens (Mart.) Coville) é uma árvore elevada e de casca áspera. Possui flores miúdas e folhas bipinadas. É utilizada em casos de hemorragia, leucorreia e blenorragia. Externamente pode ser aplicada em úlceras e ferimentos (BALBACH, 1995). Já o boldo (Peumus boldus Mol), originário do Chile, é muito utilizado para combater a má digestão, fortificando o 
estômago e os nervos. Também é indicado para hepatites, congestões do fígado, distúrbios gástricos, tonturas, insônia, cólicas intestinais e várias outras enfermidades (BOLDO-DO-CHILE, 2008).

A camomila (Matricaria chamomilla L) é utilizada na medicina popular em forma de infusão ou de chá tônico amargo, e possui a propriedade de ser calmante, digestivo, febrífugo, antirreumático, antiespasmódico e emenagogo (SOUSA et al., 1991).

O capim-santo (Cymbopogon citratus (DC). Stapf) é uma planta herbácea da família das gramíneas, oriunda da Ásia, de fácil cultivo e que possui ampla distribuição no Rio Grande do Sul. O chá de suas folhas frescas é muito utilizado na medicina popular, sendo também possível delas extrair-se o óleo essencial, que apresenta atividade contra as células leucêmicas (DUBEY et al., 1997). É citado como fortificante, digestivo, antigripal, analgésico, antitérmico, diurético, calmante e outros (GOMES; NEGRELLE, 2003).

O cajueiro roxo (Anacardium occidentale L.) possui diversas propriedades medicinais e é estimulante do organismo. Combate o diabetes, é anti-hemorrágico, e ainda pode ser utilizado em gargarejos para curar inflamações da garganta e aftas (ERVAS MEDICINAIS, 2008). Já a erva-doce (Pimpinella anisum L.) é uma erva anual que tem sido amplamente cultivada no mundo todo. Suas folhas frescas são utilizadas para temperar ou enfeitar comidas e por meio das sementes pode-se fabricar um óleo, que pode ser utilizado como medicamento, perfume, sabonete e outros (STEPHENS, 2009). Essa erva possui reputação considerável como medicamento para tosses e doenças peitorais, sendo muito utilizada em forma de pastilhas. O óleo possui ação benéfica nos brônquios, combatendo a asma e a bronquite. Também é muito utilizada para combater cólicas infantis (BOTANICAL, 2008).

O ginseng (Panax ginseng C.A Meyer) é um dos gêneros mais importantes no Oriente, onde tem sido utilizado como fonte de medicina. Diversas espécies são encontradas no hemisfério norte. A raiz do ginseng vem sendo utilizada há milhares de anos nos países da Ásia, onde é tradicionalmente usada como tônico para restauração da força. Trabalhos sugerem que o ginseng também possui atividade contra o desenvolvimento do câncer, sendo utilizado em tabletes (SHIN et al., 2000). 
O ipê-roxo (Tabebuia avellanedae Lor. ex. Griseb) é uma árvore muito empregada na medicina popular; sua casca é utilizada em forma de infuso, possuindo propriedades antiinflamatórias, anticancerígenas, cicatrizantes e antibacterianas (AMARAL et al., 2001).

O jatobá (Hymenaea courbaril L.) é uma árvore grande e copada, com flores miúdas e madeira vermelho-escura. A casca e a resina são vermífugas e estomáquicas. $\mathrm{O}$ seu chá é indicado para cistite aguda ou crônica. Também pode ser utilizado em casos de blenorreia, bronquite, tosse, dores diversas e inflamações (BALBACH, 1995).

A romã (Punica granatum L.) vem sendo bastante citada em diversos trabalhos científicos. É muito utilizada popularmente e apresenta atividade anti-inflamatória, antimicrobiana, hipoglicemiante e antioxidante. Pesquisadores têm investigado a sua utilização como agente quimioprotetor e adjuvante no tratamento do câncer, no qual tem se mostrado bastante promissora (KIM; MEHTA; YU, 2002).

Outra pesquisa semelhante à citada acima foi realizada por Elias e Alves (2002), na qual pacientes oncológicos, que eram atendidos no Hospital Universitário da Universidade de Brasília (HUB), foram entrevistados para verificação do uso de terapias não convencionais. Nesse trabalho houve a participação de 105 doentes e as neoplasias mais frequentes eram o câncer de mama, linfomas e câncer de pulmão. Do total, 67 pacientes $(63,81 \%)$ afirmaram usar ou terem usado medicina não convencional. De todos os pacientes entrevistados, 95 afirmaram nunca ter recebido qualquer orientação sobre o uso desse tipo de medicina, e 82 manifestaram o desejo de receber esclarecimentos sobre o assunto. Dos doentes que relataram o uso, $71,4 \%$ receberam indicações de uso de amigos, familiares ou vizinhos.

\section{Medicamentos para câncer à base de plantas}

A utilização de produtos naturais como agentes anticancerosos começou com a medicina popular e, através dos anos, foi se incorporando na medicina tradicional e alopática. Muitas drogas que são atualmente utilizadas na quimioterapia foram isoladas de determinadas espécies de plantas ou derivadas de um protótipo natural. 
Podemos citar como exemplo a vimblastina, vincristina, etoposídeo tenoposídeo, irinotecan, topotecan e taxanos (CRAGG et al., 1993). A vimblastina e a vincristina são alcaloides isolados da planta Catharanthus roseus (L) G. Don, que possui diversos nomes populares como pervinca de Madagascar, vinca rósea e outros. Inicialmente essas drogas foram pesquisadas como hipoglicemiantes orais, já que a planta era usada popularmente para o tratamento para diabetes. Embora os estudos dos pesquisadores não confirmassem a sua eficácia nessa área, eles acabaram verificando que esses agentes eram capazes de reduzir os glóbulos brancos e causar depressão da medula óssea em camundongos, podendo então ser utilizados em tratamentos de leucemias com significativos resultados (CRAGG; NEWMAN, 2005).

Além disso, esses alcaloides são de fase específica do ciclo celular, onde se ligam a proteínas microtubulares durante a metáfase, interrompendo então a mitose. Assim, a célula perde a capacidade de se dividir e morre (OTTO, 2002). A vincristina é mais potente em casos de leucemia linfoblástica aguda, produzindo remissões completas em cerca de 70\% dos pacientes (DEVITA JUNIOR, 1980). A vimblastina, utilizada em combinação com outros medicamentos, é indicada para as leucemias, linfomas, câncer testicular avançado, câncer de mama e de pulmão (CRAGG; NEWMAN, 2005).

Outro princípio ativo é o etoposídeo, que é um glicosídeo semissintético produzido a partir de extratos da raiz do podófilo (Podophyllum peltatum). Estudos demonstram que as podofilotoxinas atuam como inibidores da topoisomerase II nuclear, causando quebras no filamento de DNA. Possuem também a capacidade de inibir o transporte de nucleosídeos e o transporte mitocondrial de elétrons. $\mathrm{O}$ medicamento à base desse princípio ativo é indicado, em combinação com outros, principalmente para o tratamento de câncer testicular. Pode também ser utilizado contra o câncer de pulmão, linfomas e leucemia monocítica (BERTINO; SALMON, 2001).

O irinotecan é um semissintético solúvel em água, derivado da camptothecina, que é um alcaloide isolado da casca de uma árvore chinesa (Camptotheca acuminata Decne). A camptothecina avançou em estudos clínicos nos anos 70 e, mesmo apresentando alguma atividade antitumoral, era insolúvel em água e pos- 
suía efeito tóxico imprevisível, levando a interrupção de sua futura avaliação. O interesse renovado na camptothecina foi motivado pela identificação da topoisomerase I como alvo principal nos anos 80. A descoberta desse novo mecanismo de ação estimulou esforços dirigidos para a síntese de análogos mais solúveis em água, tendo um perfil tóxico mais favorável e consistente atividade antitumoral. $\mathrm{O}$ irinotecan exibe significativa atividade contra os carcinomas gástrico, pulmonar, pancreático e cervical, e ainda tumores do sistema nervoso central de grau elevado, linfomas e leucemia (GRIVICICH et al., 2001).

Os taxanos são agentes antineoplásicos derivados da casca do Taxus brevifolia Nutt, e incluem o paclitaxel e o docetaxel. Eles se ligam aos microtúbulos das células modificando a dinâmica de equilíbrio, resultando em uma paralisação do ciclo celular entre a metáfase e a anáfase. O paclitaxel é indicado principalmente para tratamento do câncer de mama e de ovário, mas também pode ser utilizado em tumores epiteliais, como o do pescoço, esôfago e pulmão. O docetaxel é um análago semissintético do paclitaxel, e também é aprovado para o uso contra o câncer de mama e de pulmão (BERTINO; SALMON, 2001).

A tabela 3 apresenta uma relação de agentes derivados de plantas em processo de investigação laboratorial no ano de 2001. Na ocasião, alguns medicamentos citados já eram utilizados na quimioterapia de pacientes cancerígenos e outros ainda estavam em fase de teste. Verifica-se o nome do composto, o tipo de câncer tratado e a fase nos testes para o período.

No final da década de 90, com a entrada em vigor da lei de propriedade industrial no Brasil e com base na Resolução da Diretoria Colegiada - RDC número 17 de 24/02/2000 da ANVISA, diversas indústrias farmacêuticas nacionais fizeram parcerias com o setor acadêmico, com a finalidade de promover o desenvolvimento de fitomedicamentos, cujos registros exigem estudos científicos para comprovação da qualidade, eficácia e segurança de uso (CALIXTO, 2003). 
Tabela 3 - Agentes anticancerígenos derivados de plantas

\begin{tabular}{|l|l|l|}
\hline Composto & \multicolumn{1}{|c|}{ Tipo de câncer } & Status \\
\hline Vincristina & $\begin{array}{l}\text { Leucemia, linfoma, mama, pulmão, cânceres } \\
\text { infantis sólidos e outros }\end{array}$ & Fase III/IV \\
\hline Vimblastina & $\begin{array}{l}\text { Mama, linfoma, células germinativas e câncer } \\
\text { renal }\end{array}$ & Fase III/IV \\
\hline Paclitaxel & Ovário, mama, pulmão, bexiga, cabeça e pescoço & Fase III/IV \\
\hline Docetaxel & Câncer de mama e pulmão & Fase III \\
\hline Topotecan & Ovário, pulmão e infantil & Fase II/II \\
\hline Irinotecan & Colorretal e pulmão & Fase II/III \\
\hline Flavopiridol & Experimental & Fase I/II \\
\hline Acronyciline & Experimental & Fase II/III \\
\hline Bruceantin & Experimental & $\begin{array}{l}\text { Pré-clínico/ } \\
\text { Fase I }\end{array}$ \\
\hline Thalicarpin & Experimental & $\begin{array}{l}\text { Pré-clínico/ } \\
\text { Fase I }\end{array}$ \\
\hline
\end{tabular}

Fonte: Rocha, Lopes e Schwartsmann (2001) modificado.

Diversos programas colaboradores vêm sendo desenvolvidos pelo Instituto Nacional do Câncer (INCA) em países como o Brasil, Costa Rica, México e Panamá, e envolvem possibilidades de novas drogas e de plantas químicas para o câncer. As florestas tropicais são bem exploradas por esses programas devido a sua alta diversidade em espécies da flora. Projetos semelhantes são desenvolvidos no mundo todo em várias instituições, como por exemplo, a Fundação Oswaldo Cruz (FIOCRUZ), no Rio de Janeiro, o Instituto de Diversidade Biológica da Costa Rica, o Instituto de Química da Universidade Nacional do México, o Instituto Kunming de Botânica da China e o Centro de Investigação do Câncer da Academia Russa de Ciências Médicas (TAYLOR, 2000).

\section{Alguns aspectos positivos quanto ao uso de plantas medicinais}

A abundância de diferentes espécies vegetais nativas e o fácil acesso que os usuários podem ter a elas são fatores que levam as pessoas a mostrarem uma preferência pela medicina alternativa. Pode-se citar também o baixo custo no preparo de infusões, por proporcionar vantagens para as populações de baixa renda (NAKAZAWA, 1999). O fato de as plantas medicinais poderem ser cultivadas no quintal da própria casa, ou na casa de familiares e de amigos, também é um ponto positivo (VIGANÓ, J.; VIGANÓ, J. A.; CRUZ-SILVA, 2007). Segundo Álvarez 
(2005), a fitoterapia, em relação à medicina moderna, tem mostrado ser mais útil quando utilizada no tratamento de certas enfermidades crônicas, apresentando menos efeitos secundários e sendo mais barata e econômica. Outra vantagem é que os medicamentos fitoterápicos podem ser associados aos medicamentos alopáticos, mas é necessário certo cuidado em relação a tal associação, pois os fitoterápicos podem potencializar os efeitos de alguns desses medicamentos. Esse uso deve ser feito sempre com o acompanhamento de um profissional da área da saúde (ARNOUS; SANTOS; BEINNER, 2005).

De acordo com Parente e Rosa (2001), outro fator de destaque na crescente procura da fitoterapia é a vigente carência de recursos dos órgãos públicos de saúde, resultando nos aumentos de preços dos medicamentos industrializados, fato que não costuma ocorrer nesse tipo de medicina.

\section{Alguns aspectos negativos quanto ao uso de plantas medicinais}

Os princípios ativos das plantas medicinais são responsáveis tanto pelas propriedades terapêuticas como pelas intoxicações e reações adversas, que podem se apresentar devido ao seu uso em doses inadequadas e/ou por períodos prolongados. $\mathrm{O}$ fato de existir uma falta de informação objetiva e atualizada sobre os possíveis riscos e benefícios do uso de plantas medicinais pode ser considerado um dos principais fatores que contribuem para a população praticar a automedicação. Por serem naturais, muitas pessoas acham que o uso das plantas medicinais é mais seguro e acabam utilizando-as incorretamente (BASTOS, 2007). O emprego de plantas medicinais, que supostamente possuem ação inofensiva à saúde, pode ser responsável por resultados desastrosos, já que uma mesma planta pode apresentar tanto ação terapêutica quanto tóxica, que vai ser definida pela dosagem utilizada e pelo modo de preparo (GOMES et al., 2001). Segundo Turolla e Nascimento (2006), muitas plantas apresentam substâncias que podem desencadear reações adversas. Tais substâncias podem estar associadas aos seus próprios componentes ou a contaminantes e adulterantes presentes nas preparações fitoterápicas, o que exige um rigoroso controle de qualidade no cultivo, na coleta, na extração dos seus constituintes e na elaboração do medicamento final. 
No Brasil, as plantas medicinais da flora nativa são consumidas com pouca ou nenhuma comprovação de suas propriedades farmacológicas. A toxicidade dessas plantas resulta em um sério problema de saúde pública, uma vez que, os efeitos adversos dos fitomedicamentos e a interação deles com outras drogas ocorrem comumente. As pesquisas realizadas para a avaliação do uso seguro e correto de plantas e fitoterápicos no Brasil ainda são precárias, assim como o controle da comercialização pelos órgãos oficiais em feiras livres, mercados ou lojas de produtos naturais (MACIEL et al., 2002).

\section{Considerações finais}

O uso das plantas medicinais como medicina não convencional é muito antigo, e, atualmente, vem apresentando um aumento significativo, principalmente nas camadas sociais mais baixas da população, já que se trata de uma forma de tratamento mais barata e de fácil acesso. Por ser uma forma natural de tratamento, tendo como base informações transmitidas de pessoa a pessoa, e, coloquialmente, por amigos, parente ou alguém considerado conhecedor do assunto, o uso das plantas transmite sensação de segurança aos usuários; contudo não são raros os casos de agravamento de doenças ou de sintomas, ou mesmo de intoxicação pelo uso inadequado ou em quantidades excessivas.

Sabe-se que o câncer é uma doença extremamente agressiva, e que os seus portadores, por motivos óbvios, tendem a se mostrar abertos a quaisquer opções de tratamento para alcançar a cura ou minorar o seu sofrimento. Nesse contexto, as pesquisas apresentadas nesta revisão mostraram que uma parte considerável dos pacientes com câncer faz uso paralelo das plantas como forma de tratamento, e que quase sempre o fazem por iniciativa própria e sem o conhecimento dos médicos responsáveis. É bastante provável, aliás, que a prática se estenda a outras doenças.

Foi possível verificar que a prática da medicina não convencional pelo uso de plantas medicinais, com base em conhecimentos empíricos transmitidos oralmente por pessoas sem formação específica, é muito comum, não só nas áreas menos povoadas, como também nos grandes centros urbanos brasileiros. 
Conclui-se que falta no Brasil uma maior integração entre usuários, reguladores, acadêmicos e legisladores visando resolver a questão, não só pelos perigos potenciais existentes no uso indiscriminado de plantas tidas como medicinais, mas também por aquilo que se poderia descobrir como novas formas de tratamento do câncer e de outras doenças. O Brasil é imenso, a sua biodiversidade enorme, mas a pesquisa é, no mínimo, incipiente.

Entrando no campo do ensino e formação de profissionais da área, percebe-se também que pouca importância é dada à fitoterapia, uma vez que a medicina convencional prefere utilizar medicamentos industrializados tidos como mais rápidos, eficazes e seguros. Aparentemente essa não é uma especialidade, e sim uma atividade auxiliar; coisa de estudiosos e pesquisadores, genericamente enquadrada dentro daquilo que se convencionou chamar de medicina alternativa, na qual predominam técnicas orientais de massagem, uso de pedras, cores e outros aparatos, e onde, por muito tempo, sobreviveram a acupuntura e a homeopatia, e que hoje são especialidades médicas reconhecidas.

Assim, é importante ressaltar a necessidade de fortalecer as pesquisas no setor para todas as disciplinas relacionadas à fitoterapia, pois ela é uma modalidade de terapia que vem crescendo em importância a cada ano no Brasil e no mundo, e que também tem o seu espaço, já que foi a precursora da atual medicina convencional.

\section{Herbal medicine in cancer treatment: a brief review}

\section{Abstract}

Cancer in its various forms, is a disease that affects the whole world and in Brazil is the second leading cause of death in adults. Their emergence and development are linked to the lifestyle of people and environmental factors to which they are exposed. Among the various therapeutic uses attributed to medicinal plants, herbal medicine is the treatment of diseases by the use of fresh or dried plants and their natural extracts. In recent years it has been taken up by conventional medi- 
cine as a more affordable and alternative treatment and has grown considerably, including cancer. But there is a great concern regarding the use of medicinal plants in home made, as its discretion and without misuse can have serious consequences. For this fact, research in this area and ways to control and guidance to the general population should be developed. Thus, the purpose of this paper is a brief review on the use of medicinal plants in treating cancer.

Keywords: Cancer. Medicinal plants. Unconventional medicine. Phytotherapy. Anticancer.

\section{Referências}

ABCÂNCER. O que é. Disponível em: <http://www.abcancer.org.br/ sobre. php?c=8\&s=18\&lang=16>. Acesso em: 4 mar. 2008.

ÁlVAREZ, T. Z. Beneficios de la fitoterapia. Revista Cubana de Plantas Medicinales, La Habana, v. 10, n. 2, p. 1-2, maio/ago. 2005.

AMARAL, F. M. M. et al. Qualidade microbiológica das cascas do caule de Tabebuia avellanedae Lor. ex Griseb. comercializadas em São Luís/Maranhão. Visão Acadêmica, Curitiba, v. 2, n. 2, p. 65-70, jul./dez. 2001.

AMERICAN CANCER SOCIETY. What are the risk factors for cancer. Disponível em: <http://www.cancer.org/docroot/CRI/content/CRI_2_4_2x_. What_are_the_ risk_fact ors_for_cancer_72.asp?sitearea=>. Acesso em: 27 fev. 2008.

ANISE. In: GRIEVE, M. Botanical.com: a modern herbal. 2008. Disponível em: <http://www.botanical.com/botanical/mgmh/a/anise040.html >. Acesso em: 14 maio 2008.

ARÁUJO, E. C. et al. Uso de plantas medicinais pelos pacientes com câncer de hospitais da rede pública de saúde em João Pessoa (PB). Espaço para a Saúde, Londrina, v. 8, n. 2, p. 44-52, jun. 2007.

ARNOUS, A. H.; SANTOS, A. S.; BEINNER, R. P. C. Plantas medicinais de uso caseiro: conhecimento popular e interesse por cultivo comunitário. Espaço para a Saúde, Londrina, v. 6, n. 2, p. 1-6, jun. 2005. 
BALBACH, A. As plantas curam. São Paulo: Vida Plena, 1995.

BARRACA, Sérgio Antonio. Babosa. In: UNIVERSIDADE DE SÃO PAULO. Plantas medicinais. 2008. Disponível em: <http://ci-67.ciagri.usp.br/pm/ver_1pl. asp>. Acesso em: 7 maio 2008.

BASTOS, G. M. Uso de preparações caseiras de plantas medicinais utilizadas no tratamento de doenças infecciosas. 2007. $111 \mathrm{f}$. Dissertação (Mestrado em Ciências Farmacêuticas. Farmácia Clínica)-Faculdade de Farmácia, Ondotologia e Enfermagem, Universidade Federal do Ceará, Fortaleza, 2007.

BERTINO, J. R. Princípios de neoplasia. In: THORN, G. W. Harrison Medicina interna. 8. ed. Rio de Janeiro: Guanabara Koogan, 1980. p. 1710-1715.

BERTINO, J. R.; SALMON, S. E. Princípios de terapia do câncer. In: BENNETT, G. Tratado de medicina interna. 21. ed. Rio de Janeiro: Guanabara Koogan, 2001. p. 1178-1194.

BHUVANESWARI, V. et al. Tomato and garlic by gavage modulate 7,12-dimethylbenz[a] anthracene-induced genotoxicity and oxidative stress in mice. Brazilian Journal of Medical and Biological Research, [S.l.], v. 37, n. 7, p. 1029-1034, jul. 2004. doi:10.1590/S0100-879X2004000700012

BLOCK, E. et al. Organosulfur chemistry of garlic and onion: recent results. Pure and Applied Chemistry, Carolina do Norte, v. 65, n. 4, p. 625-632, 1993.

BODMER, W. F. Hereditariedade e suscetibilidade ao Câncer. In: FRANKS, L. M.; TEICH, N. Introdução à biologia celular e molecular do câncer. São Paulo: Roca, 1990. p. 89-105.

BOLDO-DO-CHILE. In: UNIVERSIDADE DE SÃO PAULO. Plantas Medicinais. 2008. Disponível em: <http://ci-67.ciagri.usp.br/pm/ver_1pl.asp >. Acesso em: 5 maio 2008.

BRASIL. Agência Nacional de Vigilância Sanitária. Resolução RDC no 48, de 16 de março de 2004. Dispõe sobre o registro de medicamentos fitoterápicos. Diário Oficial da União, Poder Executivo, Brasília, DF, 18 mar. 2004. Disponível em: <http://e-legis.anvisa.gov.br/leisref/public/showAct.php?id=10230\&word $>$. Acesso em: 18 mar. 2008.

BROWN, K. et al. Importance of genetic alterations in tumour development. Archives of Toxicology Supplement, Berlin, v. 16, p. 253-260, 1994. 
CAJUEIRO: Anacardium occidentale. Ervas medicinais. 2008. Disponível em: $<$ http://guia.mercadolivre.com.br/ervas-medicinais-z-consulta-utilizaco-gratis5144-VGP>. Acesso em: 15 maio 2008.

CALIXTO, J. B. Biodiversidade como fonte de medicamentos. Revista Ciência e Cultura, Campinas, v. 55, n. 3, p. 37-39, jul./set. 2003.

CÂNCER no Brasil: presente e futuro. Revista da Associação Médica Brasileira, São Paulo, v. 50, n. 1, p. 1, 2004. doi: 10.1590/S0104-42302004000100001

CRAGG, G. M. et al. The taxol supply crisis new nci policies of novel natural product anticancer for handling the large-scale production and anti-HIV agents. Journal of Natural Products, Washington, v. 56, n. 10, p. 1657-1668, oct. 1993. doi:10.1021/np50100a001

CRAGG, G. M; NEWMAN, D. J. Plants as a source of anti-cancer agents. Journal of Ethnopharmacology, Ireland, v. 100, n. 1-2, p. 72-79, May 2005. doi:10.1016/j. jep.2005.05.011

DEVITA JUNIOR, V. T. Princípios de terapia do câncer. In: THORN, G.W. Harrison. Medicina interna. 8. ed. Rio de Janeiro: Guanabara Koogan, 1980. p. 1725-1747.

DUBEY, N. K. et al. Cytotoxicity of essential oils of Cympobogon citratus and Ocinum gratissimum. Indian Journal of Pharmaceutical Sciences, Bombay, v. 59, n. 5, p. 263-264, 1997.

ELIAS, M. C.; ALVES, E.; TUBINO, P. Uso de medicina não convencional em crianças com câncer. Revista Brasileira de Cancerologia, Rio de Janeiro, v. 52, n. 3, p. 237-243, 2006.

ELIAS, M. C; ALVES, E. Medicina não convencional: prevalência em pacientes oncológicos. Revista Brasileira de Cancerologia, Rio de Janeiro, v. 48, n. 4, p. 523532, out./dez. 2002.

FLETCHER, D. M. Unconventional cancer treatments: professional, legal and ethics issues. Oncology Nursing Forum, [S.1.], v. 19, p. 1351-1354, oct. 1992.

FRANKS, L. M. O que é o câncer? In: FRANKS, L. M; TEICH, N. Introdução à biologia celular e molecular do câncer. São Paulo: Roca, 1990. p. 1-24. 
GOMES, E. C. et al. Plantas medicinais com características tóxicas usadas pela população do município de Morretes, PR. Visão Acadêmica, Curitiba, v. 2, n. 2, p. 77-80, jul./dez. 2001.

GOMES, E. C; NEGRELLE, R. R. B. Cymbopogon citratus (D.C.) Stapf: aspectos botânicos e ecológicos. Visão Acadêmica, Curitiba, v. 4, n. 2, p. 137-144, jul./dez. 2003.

GRIVICICH, I. et al. Irinotecan and oxaliplatin: an overview of the novel chemotherapeutic options for the treatment of advanced colorectal cancer. Brazilian Journal of Medical and Biological Research, [S.1.], v. 34, n. 9, p. 10871103, sept. 2001. doi:10.1590/S0100-879X2001000900001

HOPE FOR CANCER. Célula cancerígena da mama. Disponível em: <http:// www.alternative-cancer.net/Cell_photos.htm>. Acesso em: 2 mar. 2008.

INSTITUTO NACIONAL DO CÂNCER. Como se comportam as células cancerosas? Disponível em: < http://www.inca.gov.br/conteudo_view. asp?id=318>. Acesso em: 29 fev. 2008a.

INSTITUTO NACIONAL DO CÂNCER. Incidência de câncer no Brasil: estimativa para 2008. Disponível em: <http://www.inca.gov.br/Estimativa/2008/ index.asp?link=tbregioes_consolidado.asp\&ID=1>. Acesso em: 6 mar. 2008b.

INSTITUTO NACIONAL DO CÂNCER. Tipos de câncer. Disponível em: < http://www.inca.gov.br/>. Acesso em: 5 mar. 2008c.

KIM, N. D.; MEHTA, R.; YU, W. P. Chemopreventive and adjuvant therapeutic potential of pomegranate (Punica granatum) for human breast cancer. Breast Cancer Research Treatment, [S.1.], v. 71, n. 3, p. 203-217, Feb. 2002. doi:10.1023/A:1014405730585

KLIGERMAN, J. Desafios para a oncologia brasileira no novo milênio. Revista Brasileira de Cancerologia, Rio de Janeiro, v. 45, n. 4, p. 1, out./dez. 1999.

LUZ, L. A. Producción de plantas medicinales a pequeña escala: una necesidad de la comunidad. Revista Cubana de Plantas Medicinales, La Habana, v. 2, p. 63-66, mayo/agosto 2001 .

MACIEL, M. A. M. et al. Plantas medicinais: a necessidade de estudos multidisciplinares. Quimica Nova, São Paulo, v. 25, n. 3, p. 429-438, 2002. doi:10.1590/S0100-40422002000300016 
MOTA, D. K. A. S. et al. Plantas medicinais indicadas como anti-inflamatórios por "raizeiros" da região de Goiânia. Infarma, Brasília, v. 16, n. 1-2, p. 81-82, jan/fev, 2004.

NAKAZAWA, T. A. Particularidades de formulações para fitoterápicos. Revista Racine, São Paulo, v. 9, n. 53, p. 38-41, 1999.

NEVES, M. C. M. Plantas medicinais: diagnóstico e gestão. 35. ed. Brasília: IBAMA, 2001.

OLIVEIRA, F; AKISUE, G. Fundamentos de farmacobotânica. 2. ed. São Paulo: Atheneu, 1997.

OTTO, S. E. Oncologia. 2. ed. Rio de Janeiro: Reichmann \& Affonso, 2002.

PARENTE, C. E. T; ROSA, M. M. T. Plantas comercializadas como medicinais no município de Barra do Piraí, RJ. Rodriguésia, Rio de Janeiro, v. 52, n. 80, p. 47-59, 2001 .

ROCHA, A. B.; LOPES, R. M.; SCHWARTSMANN, G. Natural products in anticancer therapy. Current Opinion in Pharmacology, [S.1.], v. 1, p. 364-369, Aug. 2001. doi:10.1016/S1471-4892(01)00063-7

SASSE, A. D. Como o câncer se forma. Disponível em: <http://www.andre.sasse. com/espcanc.htm>. Acesso em: 17 mar. 2008.

SHIN, H. R. et al. The cancer-preventive potential of Panax ginseng: a review of human and experimental evidence. Cancer Causes Control, [S.1], v. 11, n. 6, p. 565-576, jul. 2000. doi:10.1023/A:1008980200583

SIMONE, J. V. Oncologia: introdução. In: BENNETT, G. Tratado de medicina interna. 21. ed. Rio de Janeiro: Guanabara Koogan, 2001. p. 1144-1148.

SOARES, R. O. A. et al. Avaliação da capacidade antineoplásica de extratos de erva-de-passarinho Struthanthus sp. In: SIMPÓSIO DE PLANTAS MEDICINAIS DO BRASIL, 15, 1998, Águas de Lindoia. Anais... Águas de Lindoia: [S.n.], 1998.

SOUSA, M. P. et al. Plantas medicinais brasileiras. Fortaleza: EUFC, 1991.

STEPHENS, J. M. Anise: Pimpinella anisum L. The Institute of Food and Agricultural Sciences. 2009. Disponível em: <http://edis.ifas.ufl.edu/pdffiles/MV/ MV00800.pdf>. Acesso em: 6 jul. 2009. 
TAYLOR, L. Plant based drugs and medicines. Disponível em: $<$ http://www.raintree.com/plantdrugs.htm>. Acesso em: 6 jul. 2000.

THOMSON, M.; ALI, M. Garlic [Allium sativum]: a review of its potential use as an anti-cancer agent. Current Cancer Drug Targets, [S.1.], v. 3, n. 1, p. 67-81, Feb. 2003. doi:10.2174/1568009033333736

TUROLLA, M. S. R.; NASCIMENTO, E. S. Informações toxicológicas de alguns fitoterápicos utilizados no Brasil. Revista Brasileira de Ciências Farmacêuticas, São Paulo, v. 42, n. 2, p. 289-306, abr./jun. 2006. doi:10.1590/ S1516-93322006000200015

VEGA, A. G. et al. El aloe vera (Aloe barbadensis Miller) como componente de alimentos funcionales. Revista Chilena de Nutrición, Santiago, v. 32, n. 3, p. 208214, 2005. doi: 10.4067/S0717-75182005000300005

VIGANÓ, J.; VIGANÓ, J. A.; CRUZ-SILVA, C. T. A. da. Utilização de plantas medicinais pela população da região urbana de Três Barras do Paraná. Acta Scientiarum Health Science, Maringá, v. 29, n. 1, p. 51-58, 2007. doi: 10.4025/ actascihealthsci.v29i1.106 


\section{Para publicar na revista Universitas:}

Ciências da Saúde, acesse o endereço eletrônico www.publicacoesacademicas.uniceub.br. Observe as normas de publicação, para facilitar e agilizar o trabalho de edição. 